\title{
ENSAIO SOBRE A CONSTRUÇÃO HERMENÊUTICA DE UM TEMPO NARRATIVO EM MÚSICA
}

\author{
Bruno Angelo
}

\section{Resumo}

Este é um ensaio especulativo, que aborda algumas questões sobre o tempo como um fator relevante na análise musical, as quais persistem como debate aberto aqui e em outros textos concernentes à teoria da música. Qual a origem do tempo na experiência musical; e qual o nosso papel, como ouvintes, em sua concepção: tais problemáticas servem de impulso para a argumentação aqui proposta, e estabelecem a base para uma abordagem ambivalente da ideia de tempo na música, a qual envolve conceitos da fenomenologia e teoria da metáfora. Como complementação, realizo um breve estudo analítico sobre minha peça para piano intitulada Pandorga. À guisa de conclusão, implicações em relação ao impacto potencial dessa abordagem sobre a análise musical são discutidas.

\section{Palavras-chave:}

Narratividade Musical; Análise Musical; Composição.

Especular sobre nossa experiência temporal com a música é uma atividade presente em numerosos estudos recentes, especialmente aqueles oriundos da fenomenologia da música ${ }^{2}$. A premissa fundamental de semelhante empreendimento supõe que o desenrolar musical, ao inscrever-se no que podemos chamar tempo-relógio, insere ali um outro tempo, o qual já não é previsível, nem sequer mensurável, mas sim instável e predominantemente mutante. Ou seja, sobre nossa concepção artificial de um tempo-relógio (ou apesar dela) instauramos uma segunda concepção que, embora não seja menos artificial, deixa de ser convencionalmente autônoma; em qualquer que seja o caso, desde a perspectiva da teoria da música, tal premissa implica imprescindivelmente na emergência conceitual do ouvinte como criador

\section{Abstract}

This essay is a speculative approach to some questions about time as a relevant factor in musical analysis, questions that persist as an open debate here and in other texts concerning music theory. Where is the origin of time in the musical experience; and what roll do we play, as listeners, in its conception: these questions serve as an impulse for the argument proposed here, and establish the basis for an ambivalent approach to the idea of time in music, involving concepts borrowed from phenomenology and metaphor theory. As a complementation, I present a short analytical study on my piano piece called Pandorga. Finally, implications regarding the potential impact of such an approach on musical analysis are discussed.

\section{Keywords:}

Musical Narrativity; Musical Analysis; Composition.

dessa segunda temporalidade, resultado fugidio de sua tentativa de compreender o objeto musical. Assim, o caráter essencialmente subjetivo da experiência temporal em música é enfatizado por Sylvain Brétéché, dentre outros, quando afirma que "no 'correr' temporal ordinário, o tempo musical se propõe como uma revelação do presente, ou mais precisamente uma apresentação do presente; apresentação para um sujeito em presença, por um sujeito em presença" (BRÉTÉCHÉ, 2013, p. 82)33.

Os problemas concernentes ao que vai dito acima são instigantes: inicialmente, podemos nos perguntar por que 0 ato de reflexão sobre determinados eventos musicais implica numa concepção temporal, e como esta nos ajuda a apreender a sucessão desses eventos; por outro lado, é difícil estabelecer até onde tal concepção 
é, como mencionado, fruto da intervenção criativa do ouvinte sobre a obra musical, ou se ela obedece também a certos preceitos culturalmente definidos $^{4}$. Esses questionamentos são o impulso deste ensaio, e, embora não pretenda dar-lhes uma resposta cabal, espero que reflexão aqui exposta possa abrir alguma dessas portas ocultas que permeiam o estudo da teoria e análise musical, através das quais o conhecimento que geramos se espalha de maneira tão estimulante quanto imprevisível. Para tanto, buscarei relacionar meu argumento com alguns estudos que o desafiam e fundamentam, e a seguir, como complementação, apresentarei um breve exercício analítico sobre minha peça para piano intitulada Pandorga.

\section{A IMBRICAÇÃO TEMPO-ESPAÇO EM MÚSICA}

Para que se possa compreender o nascimento de uma concepção temporal a partir da reflexão sobre música é necessário que tomemos o termo que atribuímos ao apreciador da música, o ouvinte, em uma acepção mais abrangente do que a de uso comum. Isto é, necessitamos considerar o ouvinte como sendo não somente aquele que escuta a música, que a aprecia com maior ou menor atenção no seu desenrolar em tempo-relógio, mas também como aquele que busca dar-lhe múltiplos sentidos, retendo-a e transformando-a em sua memória, para além do ato auditivo. Neste sentido, o ouvinte musical pode sê-lo à distância, como por exemplo, a partir de uma partitura e sem compromisso com seu resultado cronológico, ou mesmo atribuindoIhe conceitos de ordem metafórica. Em ambos os casos, o que está em jogo é uma postura conceitual e interativa entre o ouvinte e a música que, ao manter-se constante e transcender o ato propriamente de escuta, aproxima o ouvinte das atividades de crítica e análise musical, muito embora tal associação não implique em sua "profissionalização" na área, nem muito menos na adoção de seu vocabulário técnico ${ }^{5}$.

Considerar a reflexão musical desengajada do ato de escuta como sendo "à distancia" constitui uma metáfora de relativa aceitação tácita, pois assim nos referimos a esse processo e assim poderíamos encontrá-lo caracterizado em diversos textos sobre música. Tal metáfora traz implicações consideráveis para a concepção de uma temporalidade musical, pois é a partir dela que os conceitos de tempo e espaço se confundem, sendo o segundo frequentemente invocado como meio de cognição para o primeiro. Nicholas Cook observou assim essa questão:

\footnotetext{
'Ver' eventos musicais que são temporalmente remotos entre si como constituintes de uma estrutura objetiva - isto é, percebê-los como diretamente relacionados entre si - implica uma consciência espacial, e provavelmente visual, deles. (;) Em outras palavras, música se torna forma e não apenas som na medida em que ela é experimentada espacialmente e não somente temporalmente. $\left(\right.$ COOK, 1990, p. 39) ${ }^{6}$.
}

Apontar a imiscuição do espaço sobre o tempo, em música, não implica necessariamente uma discussão de cunho filosófico. Para fins práticos, pelo menos no que se refere ao contexto deste ensaio, podemos considerar esse cruzamento conceitual como um efeito colateral de nossa interação criativa com a música, o que por sua vez explicita novamente o caráter abrangente dessa interação, simultaneamente dentro e fora do tempo-relógio, conforme argumentado acima. É curioso como Mathias Rousselot insinua uma causa para esse efeito. Ele escreve: "a espacialização do tempo é a consequência de uma tentativa de retenção do tempo cronológico, o que pode ser traduzido no plano psicológico como a não-aceitação da fuga do tempo, fuga que nos conduz inexoravelmente à morte" (ROUSSELOT, 2013, p. 73)7. Talvez por causa disso, como sugere Celso Chaves, dizer que a música é uma das artes do tempo é uma afirmação "não tão óbvia quanto parece" (CHAVES, 2010, p. 86). E, nesse sentido, é nas atividades musicais voltadas à criação que encontraremos mais exposta a imbricação espaço-tempo, possivelmente ocasionada por processos cognitivos, mas que em todo o caso invade sensivelmente a constituição de nossa cultura musical. A citação acima, de Cook, refere-se ao lado de lá da cadeia produtiva, isto é, à apreciação musical; mas facilmente reencontraremos o fenômeno transmutado do lado de cá, na composição e na performance. É assim que, por exemplo, ao escrever sobre sua própria música, Joji Yuasa considera que "temporalidade e espacialidade estão quase inseparavelmente unidas em sua natureza" (YUASA, 1993, p. 217)8. Fausto Romitelli, por sua vez, identifica entre ele e sua música "a mediação da escritura, o lugar do cálculo, da reflexão, da pesquisa, da abstração que se torna 'som', energia, comunicação". Fala em crença no "poder do olho que controla o 
ouvido" (ROMITELLI, 1999, p. 87).

Tais considerações, entretanto, não são uma exclusividade da área de música, e podem ser relacionadas a certos preceitos genéricos, concernentes à nossa cognição temporal desde perspectivas psicológicas e sociológicas. Robert Adlington, abordando a questão sob o viés da teoria da metáfora, considera a concepção do tempo como sendo "uma construção social para lidar com a mudança" (2003, p. 299) ${ }^{9}$. Já a mudança seria geralmente compreendida através de uma metáfora: a do movimento. Ou seja, nossa apreensão das transformações se daria através de caminhos traçados entre diferentes estados, donde surge a metáfora fundamental proposta por Lakoff e Johnson segundo a qual "estados são localidades" (citado em Adlington 2003, p. 300). Quando passamos a lidar especificamente com a música, frequentemente nos deparamos com uma forte tendência em associar certas transformações sonoras com o movimento, particularmente com o movimento para adiante, donde advêm não somente a necessidade de se conceber um tempo, mas também inúmeras metáforas que são moeda corrente em nossa relação verbal com a música (a tensão do elemento $\mathrm{x}$ nos conduz ao y, a música se dirige ao registro agudo...). Entretanto, argumenta Adlington, a associação entre mudança e movimento é somente uma das possibilidades de cognição das transformações sonoras que experimentamos com a música, e o autor menciona uma série de outras metáforas que implicam sensações corporais que não estão diretamente relacionadas com o moverse. Tais possibilidades acarretam em desafios para nossa concepção temporal da música que ainda estão por ser investigados, e sobre os quais quero me deter mais adiante.

Por ora, gostaria de abordar a segunda questão levantada no início deste trabalho, a saber, se podemos estabelecer em que medida nossa concepção do tempo em música se deve a certos preceitos convencionais, portanto culturais, e, por outro lado, até onde podemos julgá-la como decorrência de nosso processo criativo como ouvintes. Para tanto, tomo por ponto de partida o texto publicado por Raymond Monelle em seu livro The Sense of Music, nos quais estão expostas algumas considerações importantes a este debate.
O argumento de Monelle tem por objetivo estabelecer que música, além de conter uma temporalidade de estrutura sintática, pode também significar tempo (2000, p. 83). Tomando por fundamento estudos antropológicos e filosóficos, e resguardando-se ao contexto específico da música clássica europeia, o autor considera que, nos termos semânticos explicitados acima, duas temporalidades distintas podem ser atribuídas ao desenrolar musical: uma lírica, outra progressiva. A primeira, vinculada implicitamente a uma espécie de estado natural da música, seria de natureza holística, ou seja, se manifestaria de maneira cíclica e não progressiva, tornando os conceitos de passado e futuro irrelevantes e sendo percebida, portanto, como um presente contínuo. De fato, podemos inferir que, em se considerando exclusivamente essa temporalidade lírica, o próprio esforço de Monelle em identificá-la seria irrelevante, já que o autor a identifica com um estado sem tempo (2000, p. 86).

Já a temporalidade progressiva, como o próprio nome anuncia, estabelece o avanço semântico do tempo, ou, para aproveitar a metáfora música/espaço recém comentada, o avanço da música de um lugar para outro. Manifestase em estruturas musicais específicas e que, no que se refere à música clássica europeia, podem ser datadas objetivamente: é a partir da seconda prattica que, segundo Monelle, os primeiros sistemas progressivos passam a se desenvolver. Monelle aponta o holandês Frits Noske como primeiro teórico a identificar esse fenômeno, quem desenvolveu um estudo sobre diversas peças para teclado de J. P. Sweelinck, intitulado "forma formans", no qual a concepção de uma temporalidade progressiva é o principal argumento analítico (NOSKE, 1976, p. 43-62).

Desde já podemos facilmente inferir que a concepção de uma temporalidade progressiva depende fundamentalmente de sua cognição por metáfora de movimento. Monelle Ihe reserva adjetivos bastante sugestivos, vinculando-a com propulsão, passagem, orientação, direcionamento, entre outros (cf. MONELLE, 2000, p. 86-110). Noske, por sua vez, é bem mais direto: "em música, fatores estruturais surgem através do movimento. São fatores de tempo, afetando nossa experiência temporal. Eles causam desvios psíquicos do tempo-relógio e portanto podem ser assinalados como categorias de tensão" (NOSKE 1976, p. 47, 
grifo do autor $)^{10}$. Entretanto, e apesar de preservar a metáfora movimento/tempo, o argumento de Noske objetiva propor a não-espacialização do tempo na música, suprimindo a ideia de "objetos" musicais, os quais seriam essencialmente a matéria da teoria musical tradicional, e substituindo-a por aquilo que denomina "fatores [de tempo] no processo musical". Sendo assim, o autor limita seus "fatores estruturais fundamentais" a apenas três, todos claramente ligados à ideia de movimento: aceleração, desaceleração e estabilização (NOSKE, 1976, p. 44-47) ${ }^{11}$.

Aqui começam os problemas. Pois, ainda em um contexto marcadamente experimental, como o é o artigo de Noske, tais fatores estruturais devem finalmente ser apresentados como representações de movimento. Noske os aponta como movimentos, mas em última instância, ao considerar as variações de velocidades nos cânones de Sweelinck, ele as apresenta em partitura, ou em relações numéricas que representem suas proporções macro e microestruturais. Ou seja, a imbricação espaço-tempo permanece como problema a ser considerado, e ainda que Noske dirija nossa atenção para o movimento e não para o objeto em si, tais elementos tendem a confundir-se na apreensão da análise, de maneira que fica difícil separar um do outro. $O$ autor reconhece esse desafio, e prevê um longo caminho investigativo antes que possamos abordar com clareza a forma formando-se a si mesma, forma formans, e não somente a forma formata. Em sua conclusão, Noske observa, não sem pesar, uma (ainda) inevitável confusão entre espaço e tempo, em parte porque a própria teoria da música está "atolada em termos espaciais indicando conceitos de tempo" (NOSKE, 1976, p. 58) .

Minha proposta é considerar o desafio musical de tempo-espaço como sendo, ao menos em parte, falso. Isso porque podemos enxergar a temporalidade em música, ainda no nível semântico evocado por Monelle, de duas maneiras distintas e complementares. A primeira é aquela vinculada à fenomenologia da música, segundo a qual certas disposições de elementos musicais nos propiciam uma experiência temporal, o que implica dizer que "percebemos" o tempo da música movimentar-se, e, portanto, avançar. Essa percepção, em grande parte, não depende do ouvinte singular como criador do tempo, mas atém-se a preceitos culturais que podem ser identificados historicamente. É o caso do próprio estudo de Monelle, que busca dar conta de como diversos gestos musicais progressivos desenvolvidos durante o período barroco foram aproveitados no classicismo como condução entre temporalidades líricas, propiciando assim a concepção do que hoje chamamos narratividade em música. No caso das peças de Sweelinck analisadas por Noske, basta-nos um pouco de força de vontade para que possamos experimentar (ou ao menos entrever) prospectivamente, através das representações oferecidas, o movimento dos materiais composicionais como fator estrutural mais significativo que os materiais em si.

Entretanto, quando passamos à dialética entre as temporalidades lírica e progressiva proposta por Monelle, a situação se transforma: já não se trata exclusivamente de experimentar, com maior ou menor grau de consciência, uma temporalidade musical; aqui, torna-se necessário conceber o tempo, e é principalmente neste caso que a atuação criativa do ouvinte, entendido na acepção abrangente antes estipulada, tornase imprescindível. Monelle, como mencionado, mantém seu foco de estudo sobre a dialética temporal na música clássica europeia e em seus desdobramentos no século XIX. Ele assim considera a dualidade temporal:

\begin{abstract}
(...) eventos passados na sonata poderiam ser situados na memória (;). Uma frase que conforma o principio de uma unidade lírica ainda em performance não está no passado: ela é parte do presente, e não pode ser lembrada. Somente a enunciação lírica completa pode ser alocada na memória, e isso requer que ela seja relegada ao tempo passado através de uma mudança progressiva na temporalidade, a qual não deve ser identificada como uma unidade lírica. (MONELLE, 2000, p. 110, grifo do autor) ${ }^{12}$
\end{abstract}

Podemos expressar mais diretamente tal observação, considerando que a dialética entre as temporalidades lírica e progressiva propicia o encadeamento de instâncias cíclicas, onde a própria concepção do avanço do tempo seria irrelevante porque inexistente, se essas não estivessem permeadas por instâncias progressivas, as quais permitem a instauração de uma memória musical, isto é, de um passado com o qual afrontar o presente. Permitem a quem? A nós, ouvintes. Em todo o caso, já não se trata de perceber o tempo, mas sim de criá-lo. E quando a coisa desce para o exercício da análise, bem, aí começamos a pisar em ovos, pois a determinação do momento em que o 
lírico passa a ser progressivo frequentemente recai sobre critérios essencialmente subjetivos.

Considerando o caso da sonata clássica, poderíamos tentar estabelecer premissas genéricas, tomando, por exemplo, as regiões temáticas por temporalidades líricas e transições e desenvolvimentos por temporalidades progressivas. Esse é uma tendência implicitamente sugerida por Monelle, mas o próprio autor contraargumenta tal simplificação, sobretudo porque são diversos os fatores musicais potencialmente implicantes de progressão. Ele afirma: "a ampliação de frases modulantes, o destacamento de resoluções tonais, a elaboração de cadeias de sequências - todos esses dispositivos estavam instalando tempo progressivo no seio do tempo lírico" (2000, p. 100)13. Em certa medida, não podemos separar o joio do trigo, e isso não passa despercebido por Monelle quando afirma que "o discurso barroco permaneceu concêntrico; ele progrediu por sua própria extensão, e seu objetivo era retornar para si" (2000, p. 99) ${ }^{14}$; ou quando diz que "temporalidades mistas eram quase a regra para Beethoven" (2000, p. 111)

Sem embargo, a aplicabilidade imprecisa de tais conceitos não os torna irrelevantes para a teoria da música. Sua categorização, apenas aparentemente dicotômica, pode ser considerada vaga em relação a tentativas mais detalhadas de tipologias temporais em música (cf. KRAMER, 1981 e ALMÉN; HATTEN, 2013), mas proporciona uma relação das temporalidades lírica e progressiva como pólos conceituais frutíferos para uma abordagem interpretativa através da análise musical. Sendo assim, a decorrência mais importante de sua identificação não é propriamente uma ferramenta analítica, mas sim a possibilidade adquirida de se teorizar sobre esse outro viés da temporalidade em música, o qual se estabelece interpretativamente por sobre a temporalidade perceptiva apontada pela fenomenologia. Podemos chamá-lo de tempo narrativo, em consonância com trabalhos recentes sobre narratividade em música, principalmente aqueles cujo enfoque se concretiza desde uma perspectiva analítica hermenêutica (cf., e. g., KLEIN, 2013). Para que possamos abordar concretamente semelhante conceituação, será prudente mergulhá-la brevemente num estudo teórico-empírico, donde, espero, sairemos melhor equipados para confrontá-la tanto com a discussão de fundo epistemológico que perpassa este ensaio, como também com demandas mais gerais da teoria da música concernentes à construção do tempo.

\section{O CASO DE PANDORGA}

Vejamos, então, qual pode ser o potencial de semelhante discussão sobre o exercício da análise musical. Antes de mais nada, reitero que meu objetivo aqui não é propor uma aplicação de conceitos abordados, de maneira que este estudo se configure como explanação teórica verificada por experimento prático. Trata-se, do começo ao fim, de explorar potenciais concepções de tempo narrativo em música, e dedicar-se à atividade analítica, neste caso, não será senão seguir expandindo o debate proposto até aqui: em última instância, meu interesse investigativo é o de contribuir para a ampliação da imaginação musical, neste caso abordando-a desde a teoria da música, em outros desde a composição.

Pois é justamente uma peça de minha autoria, intitulada Pandorga (no sentido de pipa de empinar), que quero trazer à tona. Ela faz parte de um pequeno ciclo de cinco peças para piano, composto em 2012 sob o título Coisas Pelo Ar. Sua duração curta (ca. 2') e a simplicidade de seus materiais, incluída aí a literal superficialidade de sua estrutura, facilitam sua rápida apreensão como objeto, ao passo em que postulam um enigma temporal instigante à luz do que venho argumentando até aqui ${ }^{16}$.

A partir dos primeiros compassos da partitura da obra, podemos identificar os elementos básicos que a compõem até o seu final (ver figura 1).

Trata-se de uma estrutura em três planos identificáveis registralmente como médio, agudo e sobre-agudo. Além disso, nessa peça, nenhuma ressonância é abafada (o pedal de sustentação permanece pressionado até o final), e um determinado nível de intensidade é vinculado a cada plano, de maneira que temos médio- $p p$, agudo-p, sobre-agudo-mf. Também podemos observar que todos os ataques estão distribuídos intermitentemente entre os diferentes planos, sendo raros os casos de concomitância no correr da peça, ao que devo acrescentar que tal distribuição não obedece a nenhum planejamento sistemático pré-composicional. Todas as escolhas se basearam num critério subjetivo de manutenção mais ou menos estável e perceptível, 


\section{Pandorga}

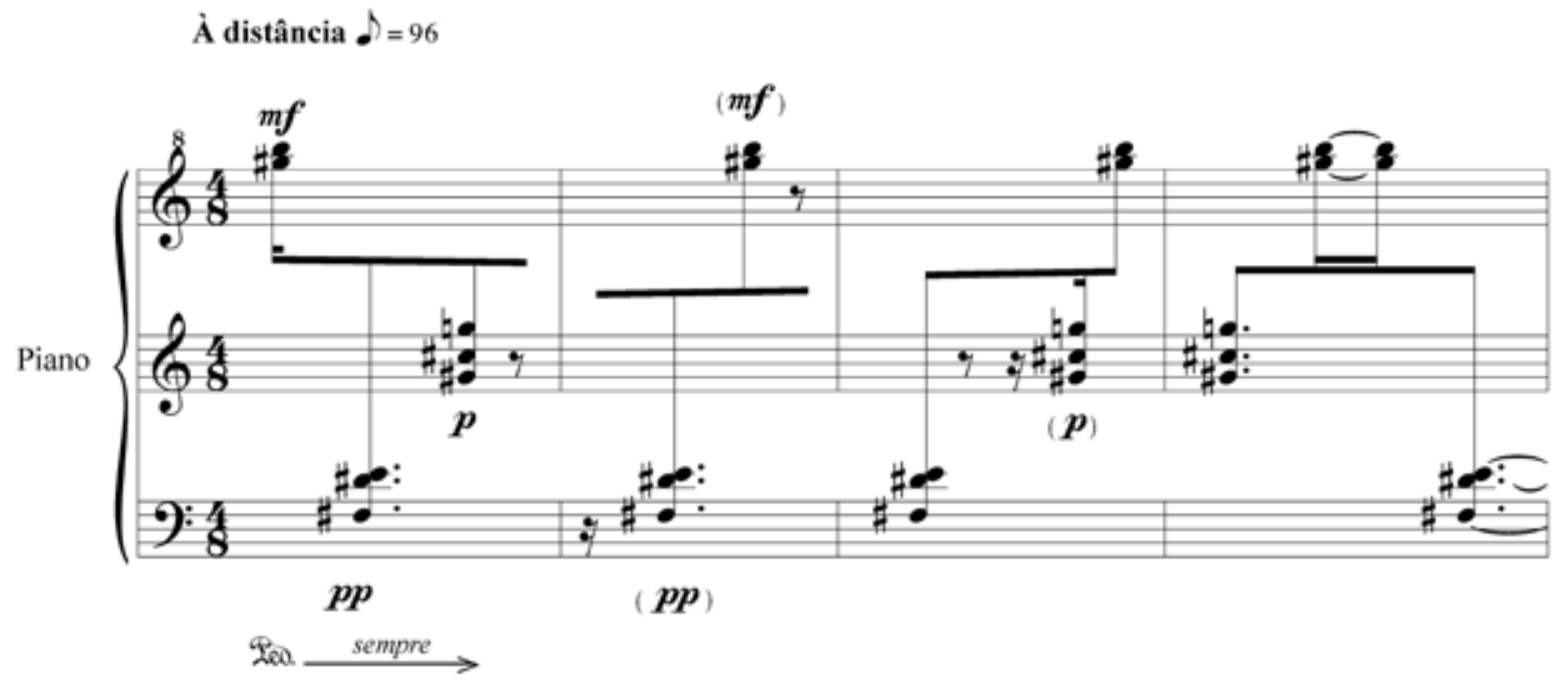

Figura 1 - Pandorga, c. 1-4.

porém não padronizada, dos três planos durante toda a peça, onde as vinculações de intensidade com os distintos registros ajudaram a equilibrar as diferenças idiomáticas de decaimento do piano.

A esta altura, podemos considerar que todos os elementos descritivos acima permitem identificar uma espécie de realidade musical. Sua atuação conjunta é, por assim dizer, a peça Pandorga. Sendo que tal realidade permanece relativamente estável até o último compasso, podemos sem hesitação outorgar-Ihe, nos termos de Monelle, uma temporalidade lírica, considerando que não há ali passado ou futuro, apenas um presente que se mantém - uma "verticalidade temporal", diria Rousselot (ROUSSELOT, 2013, p. 70-72).

No entanto, a partir do compasso que segue a fig. 1 , a peça vai passar por transformações de maior ou menor vulto, quase todas elas sutis e passageiras, e é a partir dessas transformações que emerge o problema temporal em Pandorga.

Já no c. 5, inicia-se um longo processo de transformação harmônica - que irá de fato perdurar até o final da peça -, o qual conta com relativa independência de atuação entre os três planos, e pode ser abstraído, em sua totalidade, da seguinte maneira (ver figura 2).
No primeiro bloco vertical da fig. 2 podemos observar os primeiros acordes tal qual aparecem dispostos na partitura da fig. 1. Os demais acordes da fig. 2 estão distribuídos aproximadamente de acordo com sua disposição temporal (significando, aqui, tempo-relógio) na peça, sendo que o último acorde, no plano médio (pentagrama inferior), coincide com o último ataque de Pandorga. À primeira vista podemos notar que os três planos são, no concernente a essa transformação harmônica, bastante independentes entre si, e que seu desengajamento configura uma espécie de contraponto em movimento oblíquo: enquanto o plano superagudo se mantém mais ou menos estável (a presença do sol\#/láb é praticamente constante), os planos agudo e médio empreendem uma pequena curva descendente. Além disso, no caso do plano agudo (pentagrama intermediário), essa curva é bem menor do que no plano médio, sendo que seu terceiro e último acorde se mantém presente, através da realidade musical antes descrita, até o final da peça. Por fim, consideremos que o pedal de sustentação mistura as ressonâncias, fazendo com que a passagem de um acorde a outro seja sensivelmente amenizada. Como resultado de tudo isso, ainda que possamos perceber uma mudança harmônica constante durante toda a peça, podemos considerar que a curva 


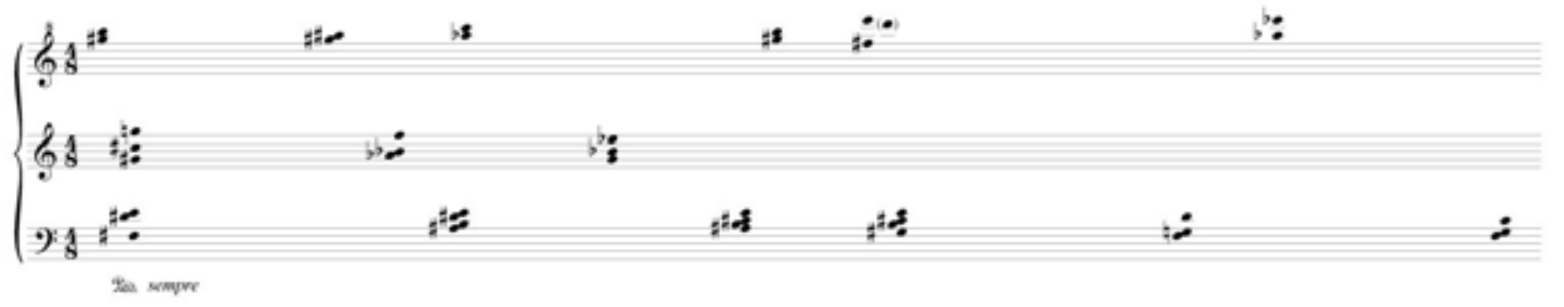

Figura 2 - Plano de transformação harmônica em Pandorga. Essa representação cobre toda a extensão da peça.

descendente, isto é, sua direção, dificilmente será percebida tal qual apontada na fig. 2 (lembremos que o tempo-relógio para o acontecimento dessa curva é de aproximadamente dois minutos).

Sobre esse processo de transformação, que abarca virtualmente toda a peça, inserem-se três outros processos pontuais, ou seja, que possuem começo, meio e fim dentro da realidade musical de Pandorga. Como veremos, trata-se de processos facilmente relacionáveis entre $\mathrm{si}$, e portanto a melhor maneira de abordá-los é a partir do primeiro deles a aparecer sobre a superfície da peça (ver figura 3).

Primeiramente, quero chamar a atenção para o pequeno processo de intensificação no plano agudo, entre os c. 5 e 6 , no ex. 2 (salientado no quadro pontilhado 1.). Note-se que há uma aceleração seguida de uma desaceleração, as quais por sua vez são acompanhadas pelo regulador de dinâmica que, embora extremamente sutil, se contrapõe à vinculação fixa de intensidades para cada plano como sendo parte da realidade musical de Pandorga. Podemos aqui seguir a ideia de Noske e considerar este processo de intensificação como sendo um fator de movimento: com isso, estamos inferindo que o principal elemento a ser observado aqui não é o material em si, mas o seu movimento de aceleração e desaceleração, acompanhado de sua intensificação e arrefecimento.

A questão temporal começa, assim, a aparecer, mas antes de encará-la de frente avancemos com a descrição dos outros dois fatores de movimento, ocorrentes respectivamente nos planos superagudo (pentagramasuperior)emédio (pentagramainferior). Um deles pode ser observado ainda ali na fig. 3, no quadro pontilhado 2. Como fator de movimento, pode ser identificado nos mesmos moldes que o anterior, apenas que expandido no tempo-relógio e no grau de intensificação da dinâmica. Já o outro, ocorrente no registro médio entre os c. 17-21, apresenta uma diferença importante: seu processo de intensificação e aceleração não é seguido por um de arrefecimento e desaceleração, como nos dois casos anteriores. Além disso sua extensão e o âmbito de intensidades que abarca ( $p p-f f$ ) são desproporcionalmente maiores do que os dos outros fatores de movimento, afetando inclusive as intensidades do plano sobre-agudo, as quais, nesse trecho, estão sob a indicação forte (ver figura 4).

Tamanha desproporção de intensidade e aceleração, apesar de ameaçadora para a realidade musical de Pandorga, desemboca num vazio - não sonoro, mas conceitual, já que o pedal de sustentação segue sempre acionado. A afetação textural é mínima, e, nos compassos que seguem até seu final, a realidade musical da peça permanece essencialmente inalterada, continuando sua transformação harmônica e mantendo sua vinculação de intensidades com cada plano: médio $-p p$, agudo $-p$, sobre-agudo-mf.

Para efeito de clareza, podemos então adaptar a fig. 2 , inserindo nela os três fatores de movimento recém discutidos (ver figura 5).

O desafio temporal em Pandorga nasce, aqui, em 

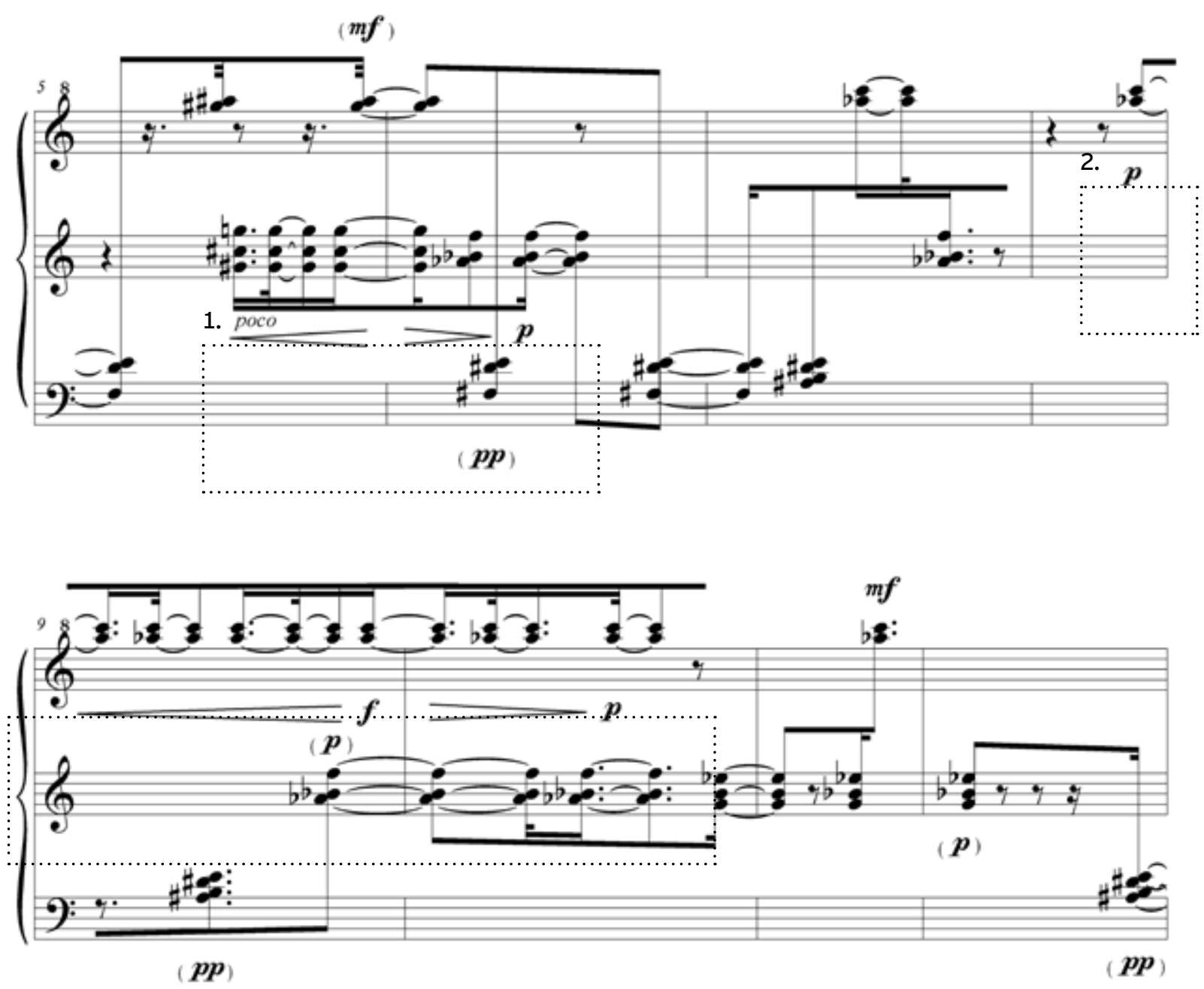

Figura 3 - Pandorga, c. 5-12. Fatores de movimento 1 e 2. 

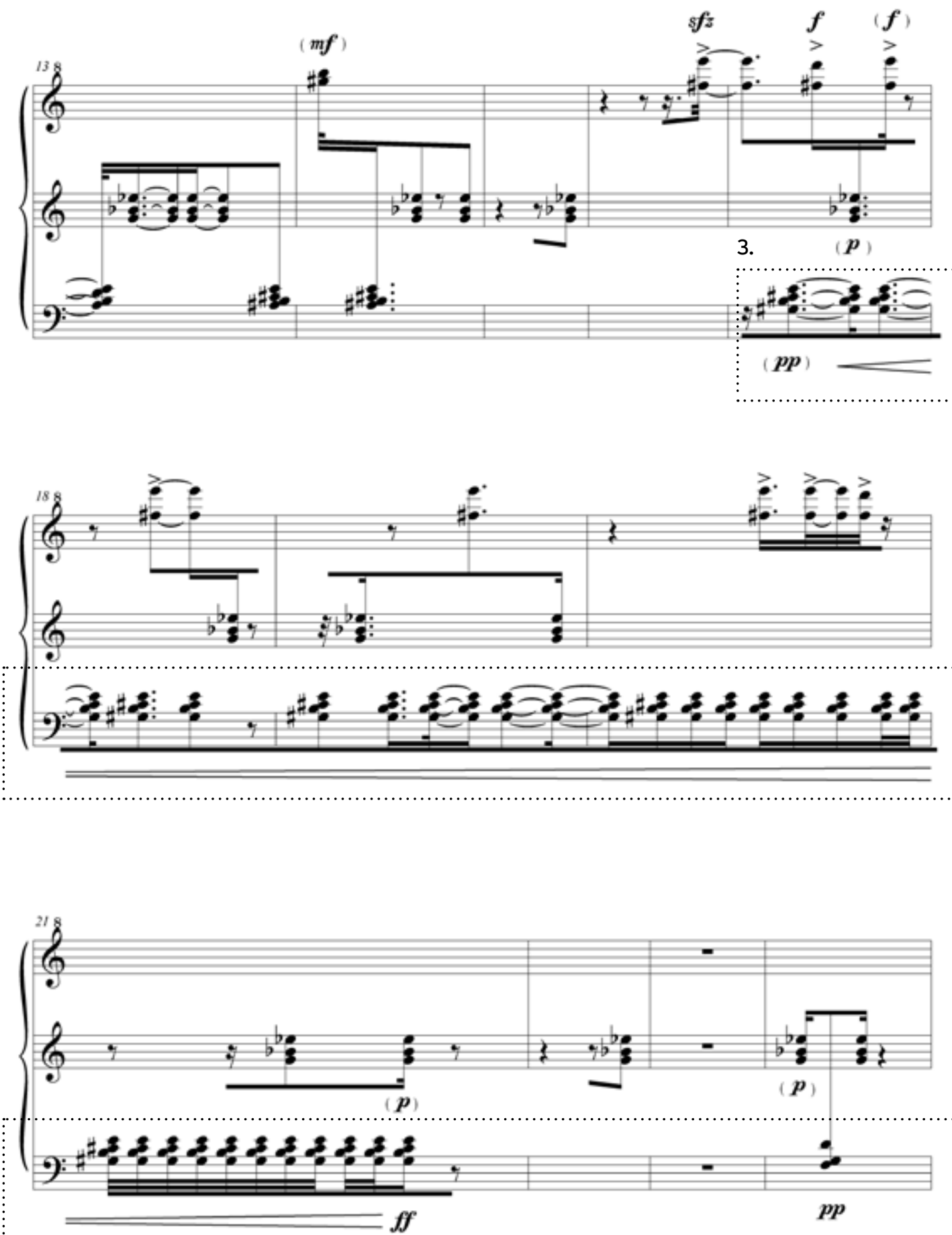

Figura 4 - Pandorga, c. 13-24. Fator de movimento 3. 


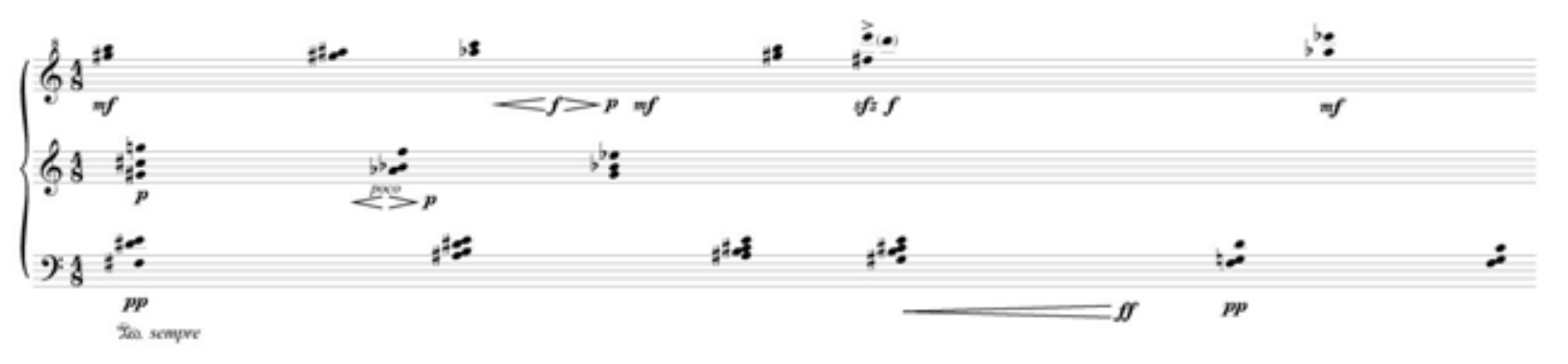

Figura 5 - plano de transformação harmônica e fatores de movimento em Pandorga.

forma de paradoxo. Se quisermos incluir em nossa interpretação narrativa a curva de transformação harmônica e os fatores de movimento, como podemos conciliá-la com a realidade musical da peça, concebida como inscrita numa temporalidade lírica, e, portanto, cíclicaenãoprogressiva?Poroutro lado, não podemos desprezar a progressividade temporal dos elementos representados na fig. 4 , que são precisamente os de maior interesse musical na peça, caracterizando-a ao (ou apesar de) contradizer sua realidade musical.

Esse problema parece pôr em xeque a dialética bicrônica de Monelle, ou, pelo menos, nos impele a definir melhor as possibilidades de mistura entre as temporalidades lírica e progressiva. Ou seja, já não se trata, aqui, de conceber uma narrativa linear, a qual responderia a uma "necessidade de alocar unidades líricas num contexto discursivo" (MONELLE, 2000, p. 98). Trata-se da necessidade de se teorizar uma concepção temporal que englobe o próprio contexto discursivo, fornecendo interpretações, por exemplo, para instâncias temporais progressivas presentes no interior de uma unidade lírica, ou mesmo para casos em que se identifica uma simultaneidade de percursos temporais interativos ${ }^{17}$. Para tanto, é preciso que abandonemos nossa cognição temporal por metáfora de movimento progressivo, e neste caso vale a pena revisitar o texto de Adlington, citado no começo deste ensaio, e considerar algumas outras metáforas possíveis quando se quer compreender as mudanças sonoras que percebemos em música.

Para Adlington, a associação das transformações musicais com o movimento não é senão uma das possibilidades cognitivas que nos oferece a nossa experiência com a música. Há outras possibilidades metafóricas comuns ao discurso sobre música que não implicam movimento, ou o fazem de maneira apenas secundária. Alguns exemplos oferecidos por Adlington são metáforas que envolvem calor, pressão, dureza, tensão, peso e luz (cf. Adlington, 2003). Segundo o autor,
tensão e relaxamento são figuras proeminentes como metáforas para transformações sonoras em textos musicológicos, mas elas são vistas tipicamente como implicadas no movimento progressivo da música, em detrimento das metáforas potencialmente autônomas, sem movimento (ADLINGTON, 2003, p. 308) ${ }^{18}$.

Inclusive as metáforas que envolvem movimento, argumenta Adlington, não implicam necessariamente movimento progressivo. Assim, por exemplo, poderíamos compreender um "movimento descendente" em música como um descenso absolutamente vertical, e não necessariamente em diagonal, como geralmente o vemos representado (2003, p. 310). Vários subterfúgios cognitivos podem ser apontados como influentes para essa tendência horizontalizante em nossa cognição das transformações musicais. Um deles, certamente não desprezível, é a relação de sons com sua distribuição representativa em partituras. A cognição do tempo como movimento linear, entretanto, parece permear todos os demais fatores (inclusive a partitura), e aqui nos debatemos novamente com o problema das temporalidades em Pandorga.

Adlington não fornece solução para a questão, pois vincula suas metáforas à cognição de mudanças 
sonoras, e desvia, por assim dizer, do problema do tempo. Tempo, para todos os efeitos, permanece sendo movimento. E música, a arte do tempo.

Para estabelecer uma concepção temporal para Pandorga, e assim dar uma conclusão a este ensaio, manterei intocada a relação tempo-movimento em seu viés fenomenológico. Entretanto, quero propor que conciliemos esta relação com um viés meta-temporal, aquele do tempo narrativo criado, feito forma, onde o movimento passa a ser secundário, embora conceitualmente presente. Quase como em consequência inevitável de tudo o que foi posto em discussão até aqui, farei uso de uma analogia temerária.

Imaginemos o tempo, em Pandorga, como sendo um lençol estendido sobre uma superfície plana qualquer. Já sabemos que tal superfície não é totalmente lisa, pois a aparente estabilidade da realidade musical da peça baseia-se em uma sucessão irregular de ataques distribuídos entre três planos registrais. Podemos conceber que cada fator de movimento antes apresentado revolve fremitamente esse lençol, alterando a visão que dele apreendemos. Sem embargo, nosso lençol não aumenta de tamanho, nem se expande pela superfície por sobre a qual se estende, antes pelo contrário; nosso tempo, a pesar de movimentarse, não avança. Por lógica, podemos agora corrigir a ideia de curva outorgada à transformação harmônica da peça (fig. 2), e dizer que esta não efetua nenhum tipo de direção linear: devemos, então, dizer que ela se encolhe, que arrefece. Trata-se sempre de uma concepção interpretativa, por certo, mas são precisamente tais decisões que potencializam nossa imaginação musical. A partir de agora, o presente da unidade lírica em Pandorga, apesar de onipresente, deixa de ser compreendido como cíclico e passa a ser vagabundo.

Podemos considerar que a analogia acima existe à revelia do objeto musical que lhe serviu de impulso criativo. Para que esse divórcio entre texto e música ficasse mais radicalmente exposto, optei deliberadamente por evitar utilizar a imagem sugerida pelo título da peça-Pandorga-, a qual, me parece, também poderia subsidiar uma analogia, que abrisse na música (ou, mais a propósito, no ouvir musical) um caminho reflexivo semelhante àquela do lençol. Minha intenção é evidenciar o percurso criativo da análise, em sua interpretação do tempo narrativo em Pandorga, como sendo a-paralelo ao processo e intenção composicional, e, além disso, apenas tangente à peça como objeto (partitura-gravação-performance). Creio que uma proximidade objetiva subjacente entre a analogia sugerida e características apontadas descritiva e fenomenologicamente na partitura está suficientemente clara, de maneira que não se poderia considerar a primeira como sendo arbitrária em relação à segunda. E, no entanto, já não poderíamos associar diretamente o conteúdo semântico da analogia, isto é, seu resultado desviante, com a estrutura da peça que lhe possibilitou a existência - elas existem, repito, uma à revelia da outra.

A discussão aqui premente pode ser exposta de forma muito direta: qual a finalidade, então, da análise? Onde reside, neste contexto, a contribuição da criação de um tempo narrativo para a música? É evidente que o propósito da análise já não pode mais ser vinculado ao seu sentido tradicional, e mesmo etimológico, o qual implicaria a dissolução ou decomposição do elemento analisado com o objetivo de melhor compreendê-lo em sua essência. A análise, aqui desinibida de seus preceitos descritivos e explicativos, atravessa perpendicularmente seu objeto como se fosse uma continuação do processo composicional, conforme venho argumentando também em outros trabalhos (cf. ANGELO, 2011a, 2011b, 2013, 2014). No campo da experiência musical, o espaço vibrante ocasionado por essa intersecção entre som e texto existe sem ser completamente um ou outro, isto é, sua manifestação é conceitual. Entretanto, para todos os efeitos, ainda estamos a falar de música, pois esse campo de experiência é ainda parte da atuação do ouvinte que aqui advogo. É nesse sentido, entre memória e imaginação, que Sophie Stévance estabelece um modo de existência para a música conceitual: ela é "realizável em pensamento: se imaginamos a ideia a propósito da música, tal como enunciada pelo artista, isso basta para fazer música" (STÉVANCE, 2009, p. 71).

A criação do tempo narrativo em Pandorga deve ser entendida, finalmente, como uma construção hermenêutica. Isso porque o que está em jogo não é a identificação do desdobramento polissêmico 
da obra, por um lado, nem tampouco a pretensão de atribuir-Ihe sua verdade, por outro. O ponto fundamental no percurso delineado neste ensaio é a composição de um sentido que a perpasse do começo ao fim, uma leitura "centrípeta", como escreve Vincent Jouve (2002, p. 94), a fim de que as questões de maior interesse para o ouvinte, em sua relação com a música, sejam extravasadas através do ato analítico.

\section{NOTAS}

1. Este ensaio é resultado de reelaboração e ampliação de uma comunicação realizada durante o III Encontro Internacional de Teoria e Análise Musical em São Paulo (ANGELO, 2013a).

2. Afora estudos seminais de Alfred Schutz (1976) e Thomas Clifton (1983), entre outros, conferir a contribuição recente de David Clarke (2011). Em âmbito brasileiro, concedo destaque aos trabalhos de Celso Loureiro Chaves (2003), Ricardo Nachmanowicz (2007) e Pedro Amorim Filho (2013).

3. 'Au seins de 'l'écoulement' temporel ordinaire, le temps musical se propose comme une révélation du présent, ou plus précisément une présentation du présent; présentation à un sujet en présence, par un sujet en présence".

4. Uma mistura entre essas duas possibilidades é a resposta aparentemente óbvia, e sem embargo a fronteira entre elas permanece como um desafio para qualquer aproximação investigativa a essa questão.

5. Poder-se-á observar, neste último ponto, uma aparente relação entre o ouvinte aqui esboçado e a famigerada tipologia de ouvintes de Adorno, particularmente a separação entre o ouvinte expert e o bom ouvinte (2009, p. 5583). Tal relação seria no entanto um equívoco, como se verá claramente em seguida. Entre outras diferenças epistemológicas, há que se considerar principalmente a relação direta entre o ouvir e a "lógica musical imanente" (ibid., p. 62), preconizada pelo autor alemão, a qual, no presente estudo, deixa de ser fundamental.

6. "To 'see' musical events that are temporally remote from each other as constituting an objective structure - that is, to perceive them as relating directly to each other - is of necessity to have a spatial, and most likely visual, awareness of them. (...) In other words, music becomes form and not just sound to the extent that it is experienced spatially and not just temporally".

7. “La spatialisation du temps est la conséquence d'une tentative de rétention du temps chronologique, ce qui pourrait se traduire sur le plan psychologique comme la non-acceptation de la fuite du temps, fuite nous amenant inexorablement vers notre mort".

8. "Temporality and spatiality in music are almost inseparably united in their natures".

9. "So in this article I treat time as, essentially, a social construction for dealing with change".

10. "In music structural factors come through as movement. They are time factors, affecting our experience of time. They cause psychic deviations from clock time and therefore may be marked as categories of tension."

11. "The professional language we use today for describing technical features of music swarms with spatial terms indicating concepts of time". Apesar de se tratar de um texto relativamente antigo, tais considerações podem ser consideradas prementes ainda hoje, haja vista o ainda incipiente desenvolvimento da teoria da música no sentido almejado pelo autor.

12. "Thus, past events in the sonata could be located in memory (...). A phrase which forms an earlier part of the lyric unit still in performance is not in the past: it is part of the present, and cannot be remembered. Only the complete lyric utterance can be placed in memory, and this requires that it be relegated to past time by means of a progressive shift in temporality which must not be identified as a lyric unit."

13. "The lengthening of modulatory phrases, the highlighting of points of tonal arrival, the constructing of chains of sequence - all these devices were installing progressive time in the midst of Iyric time."

14. "Yet the baroque discourse remained concentric; it progressed by extending itself, and its goal was to return to itself."

15. "Mixed temporalities are almost the rule for Beethoven." 
16. Partitura e gravação de Pandorga podem ser acessadas gratuitamente em meu blog pessoal: http://epopeiafantastica.wordpress.com

17. Conferir, neste sentido, o conceito de planos sonoros multidimensionais proposto por Paulo Zuben (2009), e também, numa instância criativa particularmente instigante aos desafios mencionados neste ensaio, a ideia de multiplicidade na música de Stéphane Altier, como se os instrumentos "não se conhecessem entre si" (2010, p. 72).

18. “For instance, 'tension' and 'relaxation' figure prominently in musicological texts as metaphors for changing sound, yet they are typically seen as implicated in music's forward motion, rather than as a potentially wholly autonomous, nonmotional metaphor."

\section{REFERÊNCIAS}

ADLINGTON, Robert. Moving beyond Motion: Metaphors for Changing Sound. Journal of the Royal Music Association, v. 128 no. 2, p. 297318. London: Taylor \& Francis Itd., 2003.

ADORNO, Theodor W. [1962]. Introdução à Sociologia da Música: Doze Preleções Teóricas (trad. BARROS, Fernando R. de Moraes). São Paulo: Editora Unesp, 2009.

ALMEN, Byron \& HATTEN, Robert S. Narrative Engagement with Twentieth-Century Music: Possibilities and Limits. Em: KLEIN, Michael L. \& REYLAND, Nicholas. Music and Narrative Since 1900. Bloomington: Indiana University Press, 2013, p. 59-85.

ALTIER, Stéphane. Présence, Multiplicité - Détours de L'Écriture et Raccourci du Jazz. In: STÉVANCE, Sophie. Composer au XXI e Siècle: Pratiques, Philosophies, Langages et Analyses. Bruxelles: Librairie Philosophique J. VRIN, 2010.

ANGELO, Bruno. Interpretação Narrativa: Composição de uma experiência musical através da análise. Em: Anais do II Encontro de Teoria e Análise Musical. São Paulo: IA-UNESP, 2011.

- Uma trama para Schnittke: Considerações Narrativas para o Concerto Grosso n)1. Música em Perspectiva, vol. 4 n)1. Curitiba: Programa de Pós-graduação em Música da UFPR, 2011.
Apontamentos sobre a construção do tempo em música. Anais do III Encontro de Teoria e Análise Musical. São Paulo: ECA-USP, 2013.

- Introverso e suas outras músicas. Música Hodie, vol. 13 n) 1. Goiânia: EMAC-UFG, 2013b.

\section{Minha Música Sendo Outra: a} Narratividade como Coisa Composicional. Porto Alegre: tese de doutorado defendida na UFRGS, 2014.

BRÉTÉCHÉ, Sylvain. L'incarnation de l'instant. Du movement de l'existence musicale. In: ESCLAPEZ, Christine (org.). Ontologies de la Création en Musique, vol. 2. Paris: L'Harmattan, 2013.

CHAVES, Celso L. Memória, Citação e Referência: os Fluxos do Tempo no 'Estudo Paulistano' de Celso Loureiro Chaves. Porto Alegre: Anais do XV Congresso da ANPPOM, 2003.

Por uma pedagogia da composição musical. In: FREIRE, Vanda B. (org.). Horizontes da Pesquisa em Música. Rio de Janeiro: 7Letras, 2010.

CLARKE, David. Music, phenomenology, time consciousness. EM: CLARKE, David; CLARKE, Eric (Ed.). Music and Consciousness: Philosophical, Psychological, and Cultural Perspectives. Oxford: Oxford University Press, 2011.

CLIFTON, Thomas. Music as Heard: A study in Applied Phenomenology. New Haven: Yale University Press, 1983.

COOK, Nicholas. Music Imagination and Culture. New York: Oxford University Press, 1992.

FILHO, Pedro A. Instante e fluxo: parâmetros para análise fenomenológica do tempo musical. Em: Anais do III Encontro Internacional de Teoria e Análise Musical. São Paulo: ECA-USP, 2013.

JOUVE, Vincent [1993]. A Leitura (trad. de Brigitte Hervot). São Paulo: editora UNESP, 2002.

KLEIN, Michael L. Musical Story. In: KLEIN, Michael L. \& REYLAND, Nicholas. Music and Narrative Since 1900. Bloomington: Indiana University Press, 2013, p. 3-28.

KRAMER, Jonathan D. New Temporalities in Music. Critical Inquiry, vol. 7 no. 3. Chicago, spring 1981. 
MONELLE, Raymond. The Sense of Music: Semiotic Essays. New Jersey: Princeton University Press, 2000.

NACHMANOWICZ, Ricardo. Fundamentos para uma Análise Musical Fenomenológica. Belo Horizonte: dissertação de mestrado defendida na UFMG, 2007.

NOSKE, Frits. Forma Formans. International Review of the Aesthetics and Sociology of Music, v. 7 no. 1, p. 43-62. Croatian Musicologial Society, 1976.

ROMITELLI, Fausto. Attaquons le réel a sa racine: entretien de Fausto Romitelli par Danielle CohenLevinas. Em: COHEN-LEVINAS, Danielle (org.). La Creation Après la Musique Contemporaine. Paris: L'Harmattan, 1999.

ROUSSELOT, Mathias. Instant musicien, instant musical, instant musicologique. In: ESCLAPEZ, Christine (org.). Ontologies de la Création en Musique, vol. 2. Paris: L'Harmattan, 2013.

SCHUTZ, Alfred. Fragments on the phenomenology of music. Em: SMITH, F. J. (Ed.): /N Search of Musical Method. London: Gordon \& Breach, 1976, p. 5-71.

STÉVANCE, Sophie. Duchamp, Compositeur. Paris: L'Harmattan, 2009.

YUASA, JOJI. Temporality and I: From the Composer's Workshop. Perspectives of New Music, v. 31 no. 2, p. 216-228. Perspectives of New Music, 1993.

ZUBEN, Paulo Roberto F. von. Planos Sonoros: a Experiência da Simultaneidade na Música do Século XX. São Paulo: tese de doutorado defendida na ECA-USP, 2009.

\section{Sobre o autor}

Doutor em Composição Musical (UFRGS), experiência como compositor, pianista, professor, pesquisador e produtor cultural. Dentro dessas atividades, atua em diversos concertos, festivais e congressos acadêmicos no Brasil e no exterior, publicando seu trabalho, gravando e apresentando suas composições. 


\section{Pandorga}

À distância C) $^{\prime} 96$

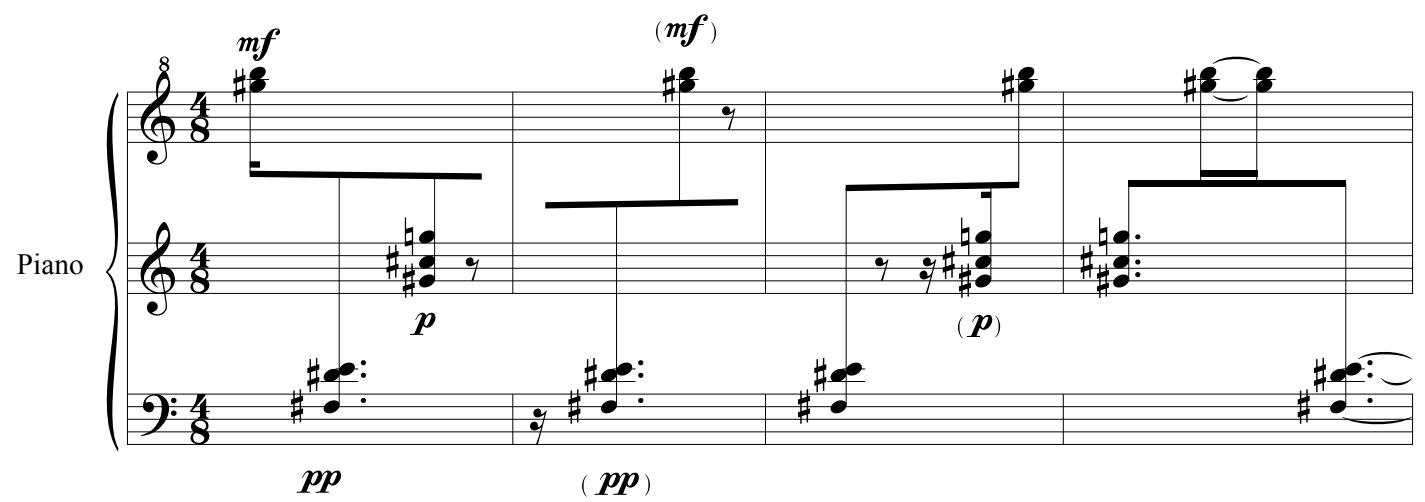

200. $\stackrel{\text { sempre }}{\longrightarrow}$
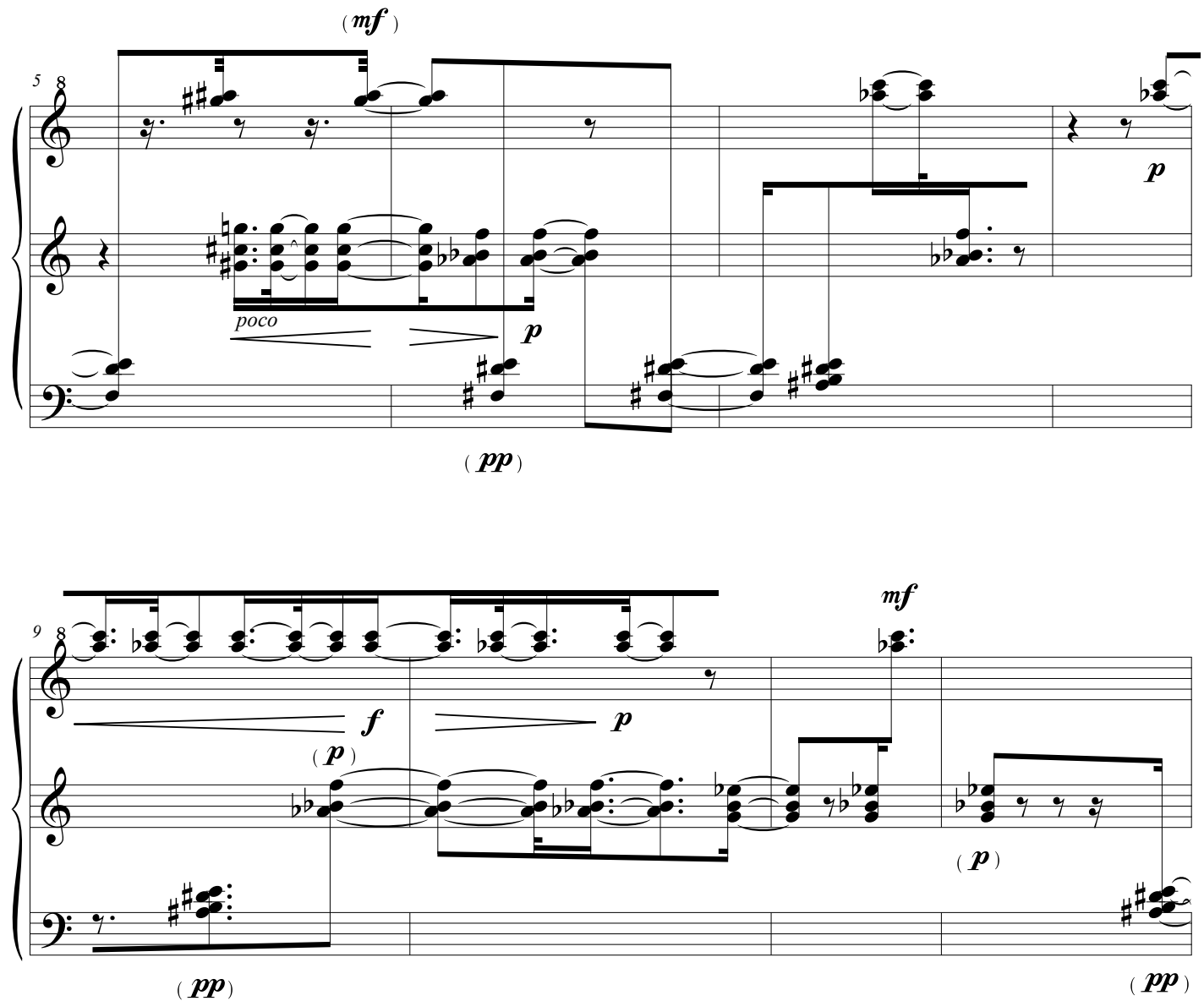

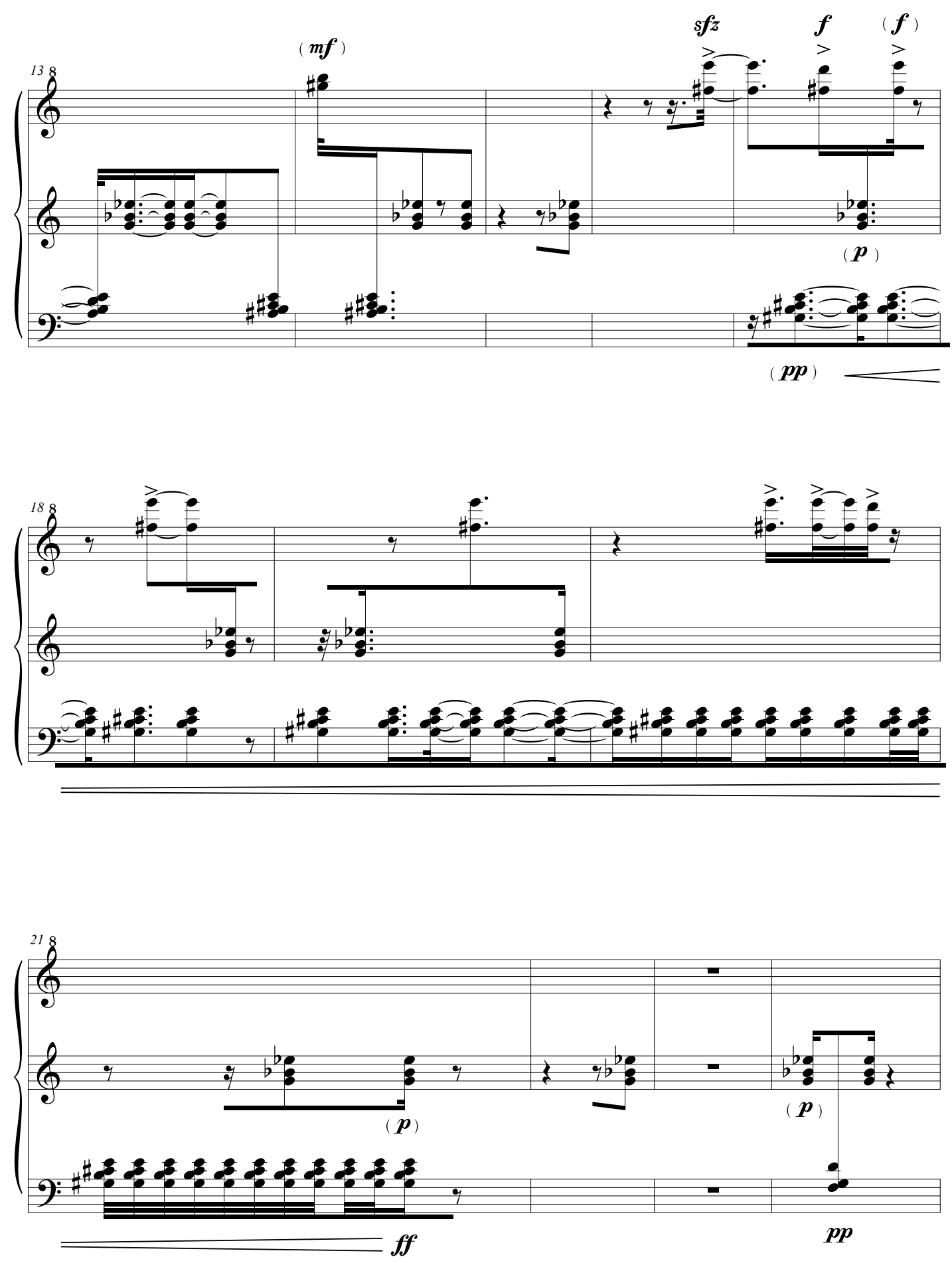

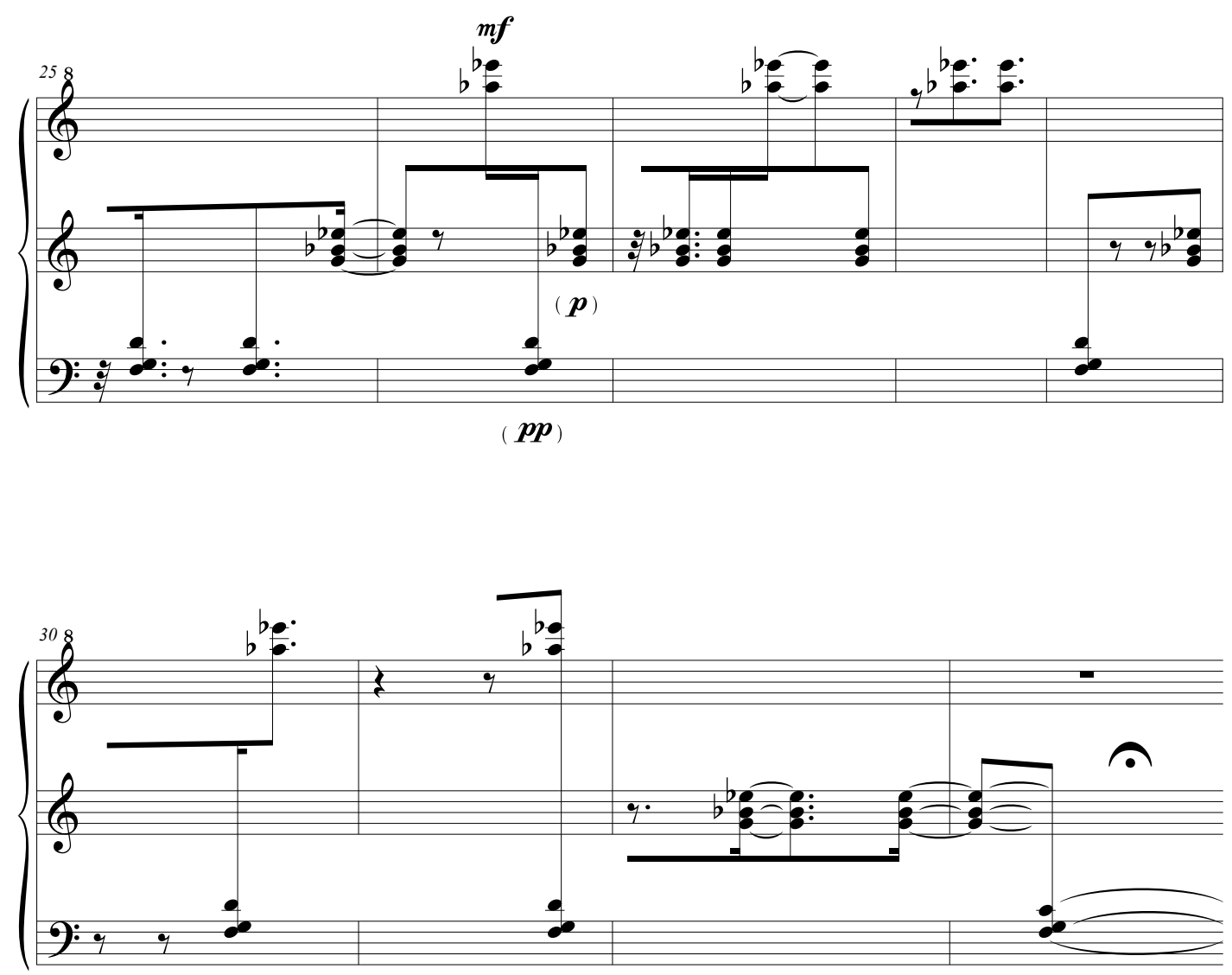

(200.)

até o final da ressonância... 